\title{
Striatal D2 Receptors Regulate Dendritic Morphology of Medium Spiny Neurons via Kir2 Channels
}

\author{
Maxime Cazorla, ${ }^{1,2}$ Mariya Shegda, ${ }^{1,2}$ Bhavani Ramesh, ${ }^{1,2}$ Neil L. Harrison, ${ }^{2,3}$ and Christoph Kellendonk ${ }^{1,2}$ \\ Departments of ${ }^{1}$ Psychiatry, ${ }^{2}$ Pharmacology, and ${ }^{3}$ Anesthesiology, Columbia University, New York, New York 10032
}

Structural plasticity in the adult brain is essential for adaptive behaviors and is thought to contribute to a variety of neurological and psychiatric disorders. Medium spiny neurons of the striatum show a high degree of structural plasticity that is modulated by dopamine through unknown signaling mechanisms. Here, we demonstrate that overexpression of dopamine D2 receptors in medium spiny neurons increases their membrane excitability and decreases the complexity and length of their dendritic arbors. These changes can be reversed in the adult animal after restoring D2 receptors to wild-type levels, demonstrating a remarkable degree of structural plasticity in the adult striatum. Increased excitability and decreased dendritic arborization are associated with downregulation of inward rectifier potassium channels (Kir2.1/2.3). Downregulation of Kir2 function is critical for the neurophysiological and morphological changes in vivo because virally mediated expression of a dominant-negative Kir2 channel is sufficient to recapitulate the changes in D2 transgenic mice. These findings may have important implications for the understanding of basal ganglia disorders, and more specifically schizophrenia, in which excessive activation of striatal D2 receptors has long been hypothesized to be of pathophysiologic significance.

\section{Introduction}

Changes in dopaminergic signaling in the striatum have been associated with multiple brain disorders including schizophrenia, drug addiction, Parkinson's disease and attention deficit hyperactivity disorder. In schizophrenia, increased occupancy and density of dopamine D2 receptors (D2Rs) have been observed in drug-free and drug-naive patients and excessive D2R activation has been associated with the positive (psychotic) symptoms of the disorder (Laruelle, 1998; Simpson et al., 2010). The striatum is important for motivational behavior and we recently found that transgenic overexpression of D2Rs in the mouse striatum leads to deficits in incentive motivation, suggesting an additional role of excess striatal D2R activation in the generation of negative symptoms of schizophrenia (Kellendonk et al., 2006; Drew et al., 2007; Simpson et al., 2011). In these mice, the motivational deficit is strongly associated with D2R overexpression since it is reversed after switching off the expression of transgenic D2Rs in the adult animal (Drew et al., 2007; Simpson et al., 2011).

Patients with schizophrenia also show structural changes in the striatum. Whereas drug-naive patients show a reduction in the volume of the striatum (Keshavan et al., 1998; Ebdrup et al., 2010), chronic treatment with typical antipsychotic medication is

\footnotetext{
Received Dec. 6, 2011; accepted Dec. 22, 2011.

Author contributions: M.C., N.L.H., and C.K. designed research; M.C., M.S., and B.R. performed research; M.C., N.L.H., and C.K. analyzed data; M.C., N.L.H., and C.K. wrote the paper.

The project was supported by the NIMH (R01MH093672) and an Irving Institute Clinical and Translational Research Grant Pilot Award. We thank Lee Gottesdiener for excellent technical assistance. We are also grateful to Jonathan Javitch, David Sulzer, Mark Ansorge, Steve Rayport, and members of the laboratory for critical comments and to Dr. Paul Slesinger for providing the HA-tagged Kir2. $1^{\text {AAA }}$ construct. Special thanks go to Eric Kandel and Eleanor Simpson with whom C.K. originally generated the D2R-OE mice.

Correspondence should be addressed to Christoph Kellendonk, Columbia University, 630 West 168th Street, Physicians \& Surgeons Bldg, Room 7-421, New York, NY 10032. E-mail: ck491@columbia.edu.

DOI:10.1523/JNEUROSCI.6056-11.2012

Copyright $\odot 2012$ the authors $\quad 0270-6474 / 12 / 322398-12 \$ 15.00 / 0$
}

associated with increased striatal volume (Chakos et al., 1994; Keshavan et al., 1994; Navari and Dazzan, 2009). Because typical antipsychotics are potent antagonists for D2Rs, it is thought that altered D2R signaling may be responsible for these volumetric changes, although the mechanisms have remained obscure.

In line with these clinical observations, medium spiny neurons (MSNs), the main output neurons of the striatum, show a remarkable degree of plasticity in the adult animal, especially with regard to the morphology of their dendrites. In animal models, psychostimulant treatment that increases extracellular dopamine levels also increases dendritic branching of MSNs (Robinson and Kolb, 2004), whereas dopamine depletion decreases dendritic arborization, a phenomenon that is also observed in Parkinson's disease (McNeill et al., 1988; Zaja-Milatovic et al., 2005). The mechanisms for this structural plasticity are unknown but their identification could reveal new drug targets for the treatment of striatal disorders including schizophrenia.

In the current study, we analyzed the morphological and electrophysiological consequences of D2R overexpression in MSNs of the mouse to determine whether increased D2R density in the striatum causes not only behavioral but also structural and functional changes. We found that chronic D2R upregulation decreases the extent of dendritic arborization of MSNs which is associated with a reduction in the volume of the striatum. Decreased arborization is further associated with membrane depolarization and increased electrical excitability, due to a reduction of inward rectifier potassium currents $\left(I_{\text {Kir }}\right)$ and Kir2 channel expression. Both hyperexcitability and dendritic atrophy are reversed after restoring D2Rs to normal levels in the adult animal, demonstrating a dynamic regulation of MSN excitability and morphology by adult D2R expression levels. Moreover, we identify Kir2 channels as important mediators of structural plasticity because downregulation of Kir2 function in vivo is sufficient to 
induce the physiological and morphological changes observed in D2R transgenic mice.

\section{Materials and Methods}

Animals. All animal protocols used in the present study were approved by the Institutional Animal Care and Use Committee at Columbia University. The generation of the D2R-OE mice has been described previously (Kellendonk et al., 2006). tetO-D2R mice have now been back-crossed for $>10$ generations onto the C57BL/6J background and CaMKII $\alpha$-tTA mice back-crossed for $>20$ generations onto 129 SveVTac. To generate D2R-OE mice, tetOD2R/C57BL6-N10 mice were crossed with CaMKII $\alpha$-tTA/129SveV-N20 mice. Only double transgenic mice express transgenic D2Rs (D2R-OE mice). Littermates carrying a single transgene (tetO or tTA) or no transgene were used as controls. The activity of tTA transcription factor was switched off by the presence of doxycycline (food application: $40 \mathrm{mg} / \mathrm{kg}$ diet). To switch off excess D2R expression, mice were fed with doxycycline for 2 weeks. Mice were genotyped by PCR as described by Bach et al. (2008). Drd2-GFP and Drd1-GFP mice were purchased from GENSAT (http:// www.gensat.org/). D2R-OE and their control littermates were analyzed on a GFP-negative C57BL/6/129SveVTac F1 background. D2R-OE mice that were crossed with either Drd2-GFP or Drd1-GFP mice resulted in a mixed background. Only male mice were used in this study. All controls were littermates. Mice were housed under a $12 \mathrm{~h} \mathrm{light/dark} \mathrm{cycle} \mathrm{in} \mathrm{a} \mathrm{temperature-}$ controlled environment with food and water available ad libitum.

Volumetric analysis. Four independent cohorts of animals were analyzed. Cohort 1: D2R-OE and control littermates ( $n=5 /$ group) were fed with regular chow from birth on until adulthood (5-6 month). Cohort 2: D2R-OE and control mice ( $n=7$ /group) were fed with doxycyclinesupplemented chow $(40 \mathrm{mg} / \mathrm{kg})$ from birth on until adulthood (5-6 month). Cohort 3: Replication of experiment 1 ( $n=5$ /group) (3-4 month). Cohort 4: D2R-OE and control mice ( $n=10 /$ group) were fed with doxycycline supplemented chow $(40 \mathrm{mg} / \mathrm{kg}$ ) for 2 weeks at 3 months of age. All four groups were perfused with $4 \%$ paraformaldehyde and incubated in 10\%, 20\% and 30\% sucrose and snap-frozen in isopentane. Coronal sections $(55 \mu \mathrm{m})$ of the entire striatum were collected on a cryostat. Sections were stained with $1 \%$ Cresyl violet and examined with a Zeiss Axioscope microscope equipped with a motorized stage (Bioprecision stage coupled with MAC 5000 controller system; Ludl Electronic Products) and digital video camera (Digital Video Camera Company). This system was interfaced with a PC-based stereology system (StereoInvestigator by MicroBrightField). The striatum was delineated as described by Franklin and Paxinos (2008). Every third section was used for the volumetric analysis averaging to $19.6 \pm 2.4$ sections per mouse. The volume was analyzed using the Cavalieri estimator.

Golgi-Cox staining and neuron reconstruction. Golgi-Cox staining was performed using FD Rapid GolgiStain kit (FD NeuroTechnologies) with modifications for optimal staining of medium spiny neurons in the mouse brain. Brains were incubated in a potassium dichromate solution for $3 \mathrm{~d}$ in the dark, then with silver nitrate for another $2 \mathrm{~d}$ before being sliced ( $150 \mu \mathrm{m}$ thickness) using a vibratome. The Golgi-Cox staining was then performed on slides. Cell bodies and dendritic arborization of medium spiny neurons in the dorsomedial striatum were traced, reconstructed and analyzed using Neurolucida (MBF Bioscience).

Slice preparation. Four-week- and 3-month-old mice were anesthetized using isoflurane and rapidly decapitated, brains were removed and then quickly submerged in ice-cold, oxygenated artificial CSF (aCSF) comprising (in mM) $1.25 \mathrm{NaH}_{2} \mathrm{PO}_{4}, 2.5 \mathrm{KCl}, 10$ Glucose, $26.2 \mathrm{NaHCO}_{3}$, $126 \mathrm{NaCl}, 2 \mathrm{CaCl}_{2}$ and $2 \mathrm{MgCl}_{2}$ (pH 7.4, 300-310 mOsm). For slice preparation, $150 \mu \mathrm{m}$-thick coronal striatal slices were cut on a vibratome in ice-cold, oxygenated aCSF. Slices were incubated in oxygenated aCSF at $32^{\circ} \mathrm{C}$ for $20 \mathrm{~min}$ followed by $1 \mathrm{~h}$ at room temperature before recording.

Whole-cell patch-clamp recording. Whole-cell voltage- and currentclamp recordings were performed using standard techniques at room temperature (Gertler et al., 2008; Jia et al., 2008). Electrodes were pulled from $1.5 \mathrm{~mm}$ borosilicate-glass pipettes on a P-97 puller (Sutter Instruments). Electrode resistance was typically $5-7 \mathrm{M} \Omega$ when filled with internal solution consisting of (in $\mathrm{mM}$ ): $130 \mathrm{~K}$-Gluconate, $5 \mathrm{NaCl}, 10$ HEPES, 0.5 EGTA, $2 \mathrm{Mg}$-ATP, and 0.3 Na-GTP (pH 7.3, $280 \mathrm{mOsm}$ ). The liquid junction potential error was $\sim 1-2 \mathrm{mV}$. Kir channel currents were defined by using $\mathrm{CsCl}(1 \mathrm{~mm})$ to block Kir channels, and these experiments were performed in the presence of tetrodotoxin (TTX, 1 $\mu \mathrm{M})$ to block voltage-dependent sodium currents. All reagents were obtained from Sigma, dissolved in bathing solution and slices were perfused at a rate of $2-3 \mathrm{ml} / \mathrm{min}$. MSNs within the dorsomedial striatum or shell of the NAc were identified under infrared differential interference contrast (IR-DIC) optics. Somatic GFP expression (from either Drd1-GFP, Drd2GFP, AAV2/1-Kir2.1 ${ }^{\mathrm{AAA}} \mathrm{GFP}$ or AAV1/2-EGFP neurons) was verified using epifluorescence microscopy to confirm cell identity before recording. Whole-cell patch-clamp recordings were obtained with a Multiclamp 700B amplifier (Molecular Devices) and data were digitized using a Digidata 1440A acquisition system (Molecular Devices) with Clampex 10 (Molecular Devices) and analyzed with pClamp 10 (Molecular Devices). Current-voltage and input-output (spike frequency) curves were determined after injecting $500 \mathrm{~ms}$ currents ranging from -150 to +350 $\mathrm{pA}$ in $10 \mathrm{pA}$ steps. Action potential (AP) firing frequency $(\mathrm{Hz})$ was determined for the first two and last two pairs of APs. Similar changes were observed for both measures; only data for the initial pair of APs are presented. Kir channel currents were determined by clamping the membrane potential for $500 \mathrm{~ms}$ from -150 to $-60 \mathrm{mV}$ in $10 \mathrm{mV}$ steps. $I_{\text {Kir }}$ was defined by subtracting the ionic currents obtained at hyperpolarized membrane potentials in the presence and the absence of $1 \mathrm{~mm}$ cesium.

Single-cell reverse transcription-PCR (RT-PCR). Inward rectifying currents were recorded as described using RNase-free intracellular solution comprising (in mM) $135 \mathrm{KCl}, 10$ HEPES, 0.5 EGTA, $3 \mathrm{MgCl}_{2}$ (pH 7.3, 280 mOsm). To increase the quality of single-cell PCR and because most of the inward currents at hyperpolarized voltage steps $(<-100 \mathrm{mV})$ are due to $I_{\text {Kir }}$ in MSNs, we shortened the recording protocol by omitting the cesium step. Intracellular mRNAs were harvested by gentle aspiration of the cytoplasm into RNase-free patch-clamping pipette and transferred to a RNase-free microcentrifuge tube containing ice-cold DEPC-treated water, $0.1 \mathrm{~m} \mathrm{DTT}$, Rnasin and $50 \mu \mathrm{M}$ oligo $(\mathrm{dT})_{20}$. Single-cell complementary cDNA was generated from mRNA using the SuperScript III CellsDirect cDNA Synthesis Kit (Invitrogen). A nested PCR was performed for detecting transgenic D2R expression using primers that specifically align to the transgenic D2R cDNA and exon 2 of the transgene-specific human growth hormone $(\mathrm{hGH})$ polyadenylation sequence (First amplification: sense primer, TGC AAC ATC CCG CCT GTC CTG TAC; antisense primer, GTG TCA AAG GCC AGC TGG TGC AGA; Second amplification: sense primer, TGG CTG GGC TAT GTC AAC AGC GCC; antisense primer, GCG TTG TCA AAA AGC CTG GA). The first amplification round consisted of $5 \mathrm{~min}$ hot start at $95^{\circ} \mathrm{C}$ followed by 35 cycles $\left(95^{\circ} \mathrm{C}\right.$ for $30 \mathrm{~s}, 63^{\circ} \mathrm{C}$ for $30 \mathrm{~s}$ and $72^{\circ} \mathrm{C}$ for $1 \mathrm{~min}$ ) performed with a programmable thermocycler (Eppendorf). The second round of PCR consisted of 35 cycles $\left(95^{\circ} \mathrm{C}\right.$ for $30 \mathrm{~s}, 63^{\circ} \mathrm{C}$ for $30 \mathrm{~s}$ and $72^{\circ} \mathrm{C}$ for $1 \mathrm{~min})$. Because the amplicon spans intron 1 of the hGH gene, the amplified reverse transcribed mRNA ( $384 \mathrm{bp}$ ) can be easily distinguished from putative genomic contamination (643 bp).

Immunoblot. Immunoblots were performed as described by Cazorla et al. (2010) with slight modifications. For Kir expression quantification, mice brains were quickly removed and striata were carefully dissected and homogenized in $10 \mathrm{~mm}$ ice-cold Tris- $\mathrm{HCl}, \mathrm{pH}$ 7.4, $320 \mathrm{~mm}$ sucrose, $5 \mathrm{~mm}$ EDTA with protease inhibitor cocktail (Complete, Roche) in a glass/Teflon-type homogenizer. Lysates were centrifuged at $3000 \times g$ for $5 \mathrm{~min}$ at $4^{\circ} \mathrm{C}$ and the supernatant was cleared by centrifugation at $20,000 \times g$ for $1 \mathrm{~h}$ at $4^{\circ} \mathrm{C}$. The pellet was resuspended in homogenization buffer (containing, in mm: 10 Tris- $\mathrm{HCl}$, pH 7.4, 320 sucrose, 5 EDTA, 150 $\mathrm{NaCl}, 1 \%$ Triton X-100, and protease inhibitor cocktail). For p-CREB and CREB quantification, mice striata were homogenized in the following (in mM): 150 ice-cold NaCl, 50 HEPES, $0.5 \%$ Triton X-100, $0.01 \%$ thimerosal, 2 sodium orthovanadate, supplemented with a cocktail of protease inhibitors. Lysates were centrifuged at $14,000 \times g$ for $20 \mathrm{~min}$ at $4^{\circ} \mathrm{C}$. Cleared supernatant was collected and protein concentration was determined using a Micro BCA protein assay (Pierce). Equal amounts of proteins were subjected to SDS-PAGE. Detection of Kir2.1, Kir2.3, GFP, $\mathrm{p}$ (Ser33)-CREB, CREB and $\alpha$-tubulin was performed using anti-Kir2.1 (1:100, NeuroMab), anti-Kir2.3 (1:100, NeuroMab), anti-GFP (1:1000, Invitrogen), anti-p(Ser33)-CREB (1:500, Cell Signaling Technology), anti-CREB (1:1000, Cell Signaling Technology), anti- $\alpha$-tubulin (1: 
10,000, Sigma) and appropriate HRP-conjugated secondary antibodies. Films were quantified by densitometry using ImageJ (NIH).

Generation of AAV2/1-Kir2.1 ${ }^{A A A}$ and viral injections. The AAV2/1Kir2.1 ${ }^{\text {AAA }}$ virus was generated by inserting the rodent HA-tagged Kir2.1 ${ }^{\text {AAA }}$ sequence into the multiple cloning site of the pAAV-IREShrGFP vector (Agilent Technologies). In the Kir2.1 ${ }^{\text {AAA }}$ sequence, the GYG motif of the pore region is replaced by three Alanine residues resulting in a dominant-negative Kir2.1 channel (Preisig-Müller et al., 2002). In the AAV2/1, the viral genome is pseudotyped with AAV1 capsid while the rep protein for virus replication and packaging is derived from AAV2. The AAV2/1-Kir2.1 ${ }^{\mathrm{AAA}}$ and control AAV1/2-EGFP viruses were produced at the Penn Vector Core (University of Pennsylvania). Both D2R-OE mice and their control littermates were bilaterally injected with $0.44 \mu \mathrm{l}$ of AAV2/1-Kir2.1 ${ }^{\text {AAA }}\left(3.1 \times 10^{12}\right.$ particles/ $\left.\mu \mathrm{l}\right)$ or AAV1/2-EGFP viruses $\left(1.8 \times 10^{13} \mathrm{particles} / \mu \mathrm{l}\right)$. Viruses were carefully pressure injected using glass pipette $(10-15 \mu \mathrm{m})$ into the dorsomedial striatum (coordinates: anteroposterior (AP), $+1.0 \mathrm{~mm}$; ML, $\pm 1.4 \mathrm{~mm}$; DV,$-3.1 \mathrm{~mm}$ ). After each injection, the pipette remained in situ for $10 \mathrm{~min}$ to minimize leaking. Mice were killed 1 month after surgeries to allow the expression of Kir2.1 $1^{\mathrm{AAA}}$ and its effects on dendritic morphology.

Biocytin staining and neuron reconstruction. Biocytin filling was performed during the recording of the neurons using standard patch-clamp techniques (see above). Briefly, biocytin (5\%) was dissolved in the intracellular solution and was injected into the soma of neurons for $15 \mathrm{~min}$ using pulses of hyperpolarizing currents (100 pA for $200 \mathrm{~ms}$ at $1 \mathrm{~Hz}$ ) whenever possible. Biocytin was allowed to diffuse along the dendrites for 45-60 min at room temperature. Slices were then incubated overnight in $4 \%$ paraformaldehyde and neurons were stained using the VectaStain ABC Elite kit (Vector Laboratories) and DAB. Medium spiny neurons were characterized based on their morphology and electrophysiological properties. Cell bodies and dendritic arborization were traced, reconstructed, and analyzed using Neurolucida.

Data analysis and statistics. Data were analyzed using Prism 5 (GraphPad) and Statview. Whole-cell patch-clamp recordings were analyzed using unpaired Student's $t$ test or one-way ANOVA (basic properties) and two-way ANOVA with repeated measures (current-voltage and spike frequency curves; $p$ values of genotype effects are given in the legends unless otherwise stated). Immunoblot densitometry was analyzed using unpaired Student's $t$ test. Morphological differences were analyzed using unpaired Student's $t$ test, one-way ANOVA or two-way ANOVA with repeated measured where appropriate ( $p$ values of genotype and treatment effects are given in the legends). Genotypes and treatments are independent variables. All statistical analyses were conducted with an $\alpha$ level of $p<0.05$. Data are presented as mean \pm SEM unless otherwise stated. $n$ values indicate the number of neurons while values in parentheses indicate the number of animals.

\section{Results \\ Striatal D2R upregulation decreases dendritic arborization of MSNs}

To study the structural consequences of chronic D2R upregulation in the striatum, we isolated brains from adult mice in which D2Rs are selectively overexpressed in striatal MSNs (D2R-OE mice; Kellendonk et al., 2006; Drew et al., 2007; Bach et al., 2008; Ward et al., 2009; Simpson et al., 2011) and from their control littermates. The volume of the striatum was determined using stereological methods. We observed a $27 \%$ reduction in the absolute striatal volume of 3- to 4-month-old D2R-OE mice when compared with their control littermates (see Fig. $6 a$ ) and a $28 \%$ reduction in an independent cohort of 5- to 6-month-old mice (Fig. 1a). In contrast, an independent cohort of D2R-OE and control mice that were raised on doxycycline after birth to prevent $\mathrm{D} 2 \mathrm{R}$ transgene expression showed no differences in striatal volume (Fig. 1a).

Because dopamine signaling has been implicated in the regulation of dendritic arborization, we determined whether changes in dendritic morphology might contribute to the decrease in striatal volume. We therefore analyzed the dendritic architecture of striatal MSNs (which constitute 95\% of striatal neurons) in D2R-OE and control mice at 1, 3 and 9 months of age. MSNs were identified by their spiny nature and characteristic dendritic architecture (Fig. 1b). Three-dimensional reconstruction of MSNs revealed that both the length and complexity of the dendritic trees progressively decrease over time in D2R-OE mice when compared with control littermates (cumulative length: 1-m, $-14 \%$; $3-\mathrm{m},-21 \%$; 9-m, $-35 \%$; number of intersections: $1-\mathrm{m},-13 \%$; $3-\mathrm{m},-20 \%$; 9-m, $-30 \%$ ) (Fig. 1c-f). This decrease in branch complexity was reflected by a reduction of the number of branch points and tips. In contrast, the number of primary dendrites emerging from the soma was not affected by D2R upregulation (Fig. 1g).

\section{Striatal D2R upregulation increases excitability of MSNs}

To investigate the mechanisms that may be responsible for the morphological changes, we determined the impact of excess D2Rs on MSN physiology. Using whole-cell patch-clamp recordings from striatal slices, we analyzed the basic membrane and firing properties of neurons in the two main striatal output projections (striatopallidal and striatonigral MSNs) in 4-week-old D2R-OE mice and control littermates. To achieve cellular specificity, D2R-OE mice were crossed with either Drd2-GFP or Drd1GFP mice that express green fluorescent protein (GFP) under the control of the D2R or the D1R gene promoter, respectively (Gong et al., 2003; Gertler et al., 2008; Matamales et al., 2009). Drd2-GFP labels exclusively MSNs in the striatopallidal pathway whereas Drd1-GFP predominantly labels neurons in the striatonigral pathway (Gertler et al., 2008; Matamales et al., 2009; data not shown). Striatopallidal or striatonigral MSNs were identified in the slice preparation using fluorescence (Fig. $2 a$ ) and were characterized by their hyperpolarized resting membrane potential (RMP) and slow depolarizing ramp potential (Nisenbaum et al., 1994) (Fig. 2b).

We first determined the passive membrane and firing properties of striatopallidal (Drd2-GFP) MSNs in the dorsal striatum of control and D2R-OE mice. We found that the current-voltage relationship was altered in D2R-OE mice, with increased electrotonic potential responses to depolarizing or hyperpolarizing current injections (Fig. 2c). We also observed a depolarized RMP (control vs D2R-OE: $-78.5 \pm 0.7$ vs $-73.5 \pm 0.9 \mathrm{mV}, p<$ $0.0001)$, increased input resistance $(192 \pm 21$ vs $358 \pm 39 \mathrm{M} \Omega$, $p<0.001)$ and decreased rheobase $(102 \pm 8$ vs $74 \pm 6 \mathrm{pA}, p<$ 0.05 ). In contrast, the AP threshold was not affected (Fig. 2e). As a consequence, in D2R-OE mice less depolarizing current was required to activate MSNs and spike frequency was enhanced, with the input-output curve shifted to the left (Fig. $2 d$ ).

We next recorded from striatonigral (Drd1-GFP) MSNs in the dorsal striatum of D2R-OE and control mice (Fig. 2). Drd1MSNs from control mice were less excitable than Drd2-MSNs, as demonstrated by a more hyperpolarized RMP (striatopallidal vs striatonigral: $-78.5 \pm 0.7$ vs $-83.2 \pm 0.9 \mathrm{mV}, p<0.01$ ), higher rheobase $(102 \pm 8$ vs $157 \pm 14 \mathrm{pA}, p<0.0001)$ and increased spike frequency (Fig. $2 d, p<0.01$ ), a finding that has previously been described (Kreitzer and Malenka, 2007; Cepeda et al., 2008; Gertler et al., 2008). As we observed for striatopallidal MSNs, striatonigral MSNs were also more excitable in D2R-OE mice than in control mice, as demonstrated by a more depolarized RMP (control vs D2R-OE, $-83.2 \pm 0.9$ vs $-78.0 \pm 1.3 \mathrm{mV}, p<$ 0.01 ), increased input resistance ( $153 \pm 19$ vs $385 \pm 47 \mathrm{M} \Omega, p<$ $0.001)$, decreased rheobase $(157 \pm 14$ vs $102 \pm 12 \mathrm{pA}, \mathrm{p}<0.01)$ and increased spike frequency (Fig. $2 d, p<0.0001$ ). We also performed similar recordings from the NAc, and observed that 

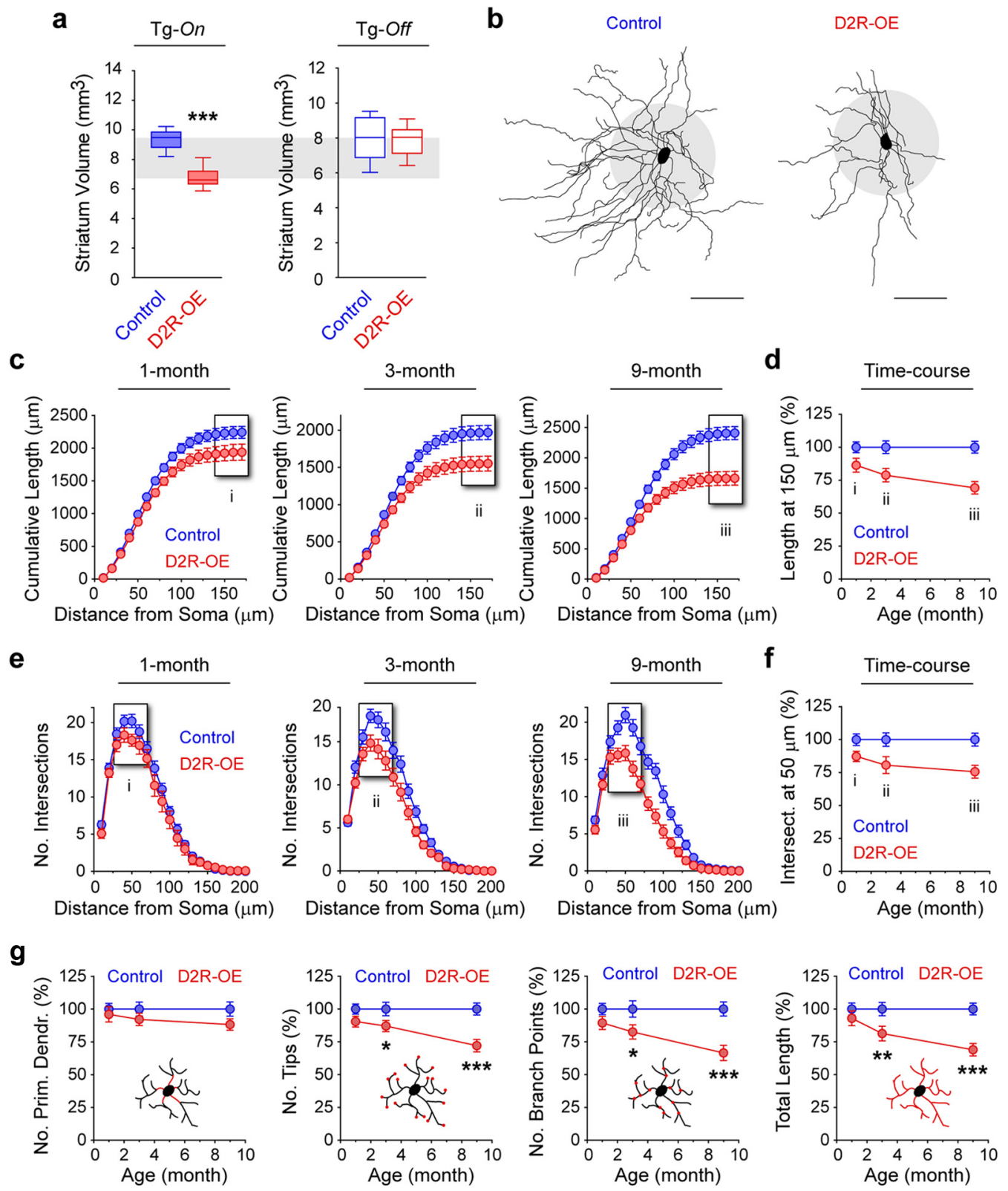

Figure 1. Progressive decrease in MSN dendritic arborization in the striatum of adult D2R-OE mice. $\boldsymbol{a}$, Striatal volumetric analysis of 5- to 6-month-old control and D2R-0E mice fed with regular lab chow (Tg-On) or with doxycycline-supplemented chow (Tg-Off) since birth. ${ }^{* * *} p<0.001$. Tg-On, $n=5$ mice/group; Tg-Off, $n=7$ mice/group. $\boldsymbol{b}$, Representative Neurolucida reconstructions of MSNs in 3-month-old control and D2R-0E mice. Scale bar/gray circle radius, $50 \mu \mathrm{m}$. (c-f) Morphological properties of MSNs at 1-, 3- and 9-month of age in control and D2R-0E mice. c-f, Cumulative length $(\boldsymbol{c}, \boldsymbol{d})$ and complexity $(\boldsymbol{e}, \boldsymbol{f})$ of MSN dendritic arborization are decreased in D2R-0E mice as young as 1 month old and worsen with age $(\boldsymbol{c}, 1$-month, $p<0.0001 ; 3$-month, $p<$ $0.0001 ; 9$-month, $p<0.0001 ; \boldsymbol{d}$, 1-month, $p=0.0002 ; 3$-month, $p<0.0001 ; 9$-month, $p<0.0001$ ). Time course graphs in $\boldsymbol{d}$ and $\boldsymbol{f}$ depict the progressive morphological atrophy measured in $\boldsymbol{c}$ and $\boldsymbol{e}$. Results are expressed as a percentage of cumulative length at $150 \mu \mathrm{m}(\boldsymbol{d})$ or number of intersections at $50 \mu \mathrm{m}(\boldsymbol{f})$ in control littermates. $\boldsymbol{g}$, Analysis of the total number of primary dendrites, branch points, branch tips and arbor length in the D2R-0E mice during adulthood. ${ }^{*} p<0.05,{ }^{* *} p<0.01,{ }^{* * *} p<0.0001$. c $-\boldsymbol{g}, 1$-month: control, $n=26$ cells (6 mice); D2R-0E, $n=16$ (5); 3-month: control, $n=36$ (6); D2R-0E, $n=26$ (6); 9-month: control, $n=20$ (5); D2R-0E, $n=20$ (5).

membrane excitability and spike frequency of both striatopallidal and striatonigral MSNs were also increased in the ventral striatum in D2R-OE mice (data not shown).

\section{Striatal D2Rs dynamically regulate excitability and morphology in adult animals}

To determine whether D2R upregulation also affects MSN excitability in the adult animal, we measured excitability in striatopallidal MSNs at 3 months of age. As observed in adolescent animals (4 weeks old), striatopallidal MSN excitability was increased in the dorsal striatum of adult D2R-OE mice (Fig. $3 a-c$ ). The RMP was more depolarized (control vs D2R-OE: $-80.3 \pm 0.8$ vs $-75.1 \pm 1.1 \mathrm{mV}, p<0.001)$ and an increase in input resistance $(160 \pm 13$ vs $407 \pm 45 \mathrm{mV}, p<0.0001)$, rheobase $(118 \pm 11$ vs $82 \pm 7 \mathrm{mV}, p<0.01$ ) and spike frequency (Fig. $3 c, p<0.0001$ ) was observed. These changes were reflected in the current-voltage relationship (Fig. 3b). Comparable results were obtained after recording from striatopallidal MSNs in the NAc of 3-month-old animals (data not shown).

To determine whether excess D2Rs are directly associated with increased excitability, we switched off transgene expression in adult mice ( 10 weeks of age) by feeding mice doxycycline ( 40 
a striatopallidal

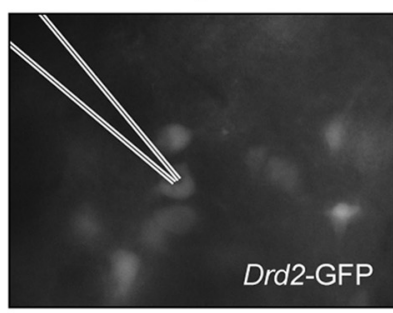

C

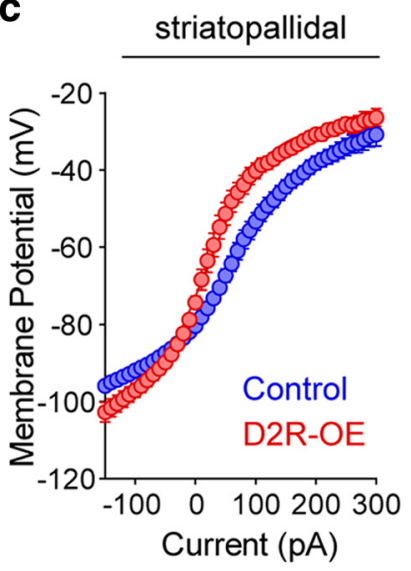

$\mathbf{e}$

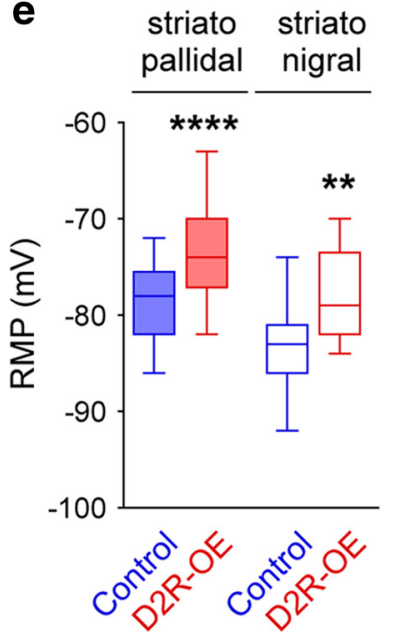

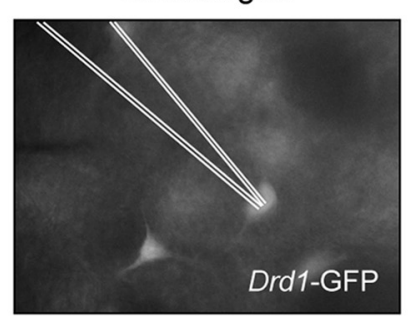

b

striatopallidal
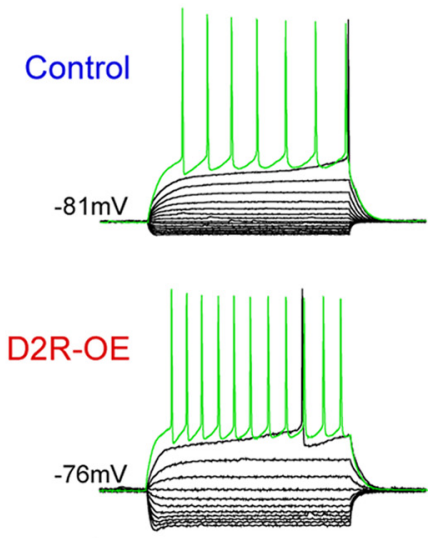

$20 \mathrm{mV}$ $100 \mathrm{~ms}$

d

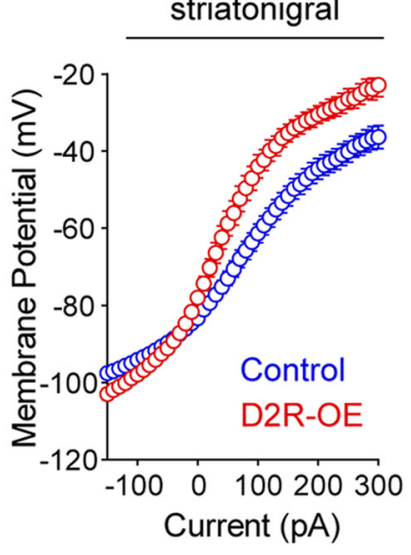

striatonigral
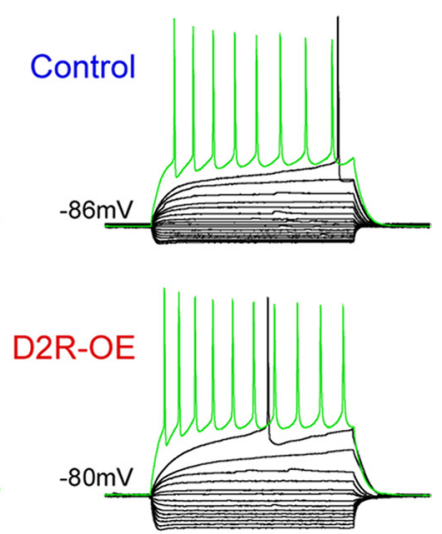

$20 \mathrm{mV}$

$100 \mathrm{~ms}$

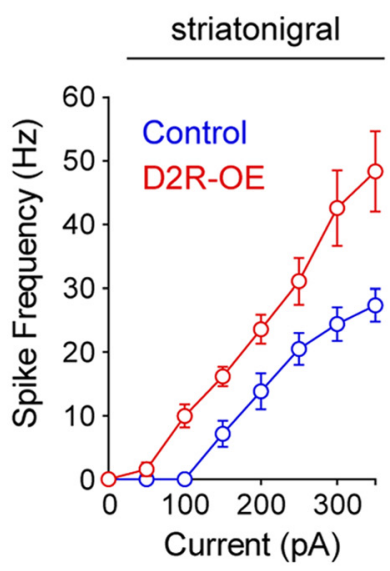

Figure 2. Chronic striatal D2R overexpression increases the excitability of striatopallidal and striatonigral MSNs. $\boldsymbol{a}$, Representative epifluorescence images of slice preparations from 1-month-old Drd2-eGFP and Drd1a-eGFP mice showing fluorescent striatopallidal and striatonigral MSNs, respectively. $\boldsymbol{b}$, Representative voltage responses obtained for striatopallidal (left) and striatonigral (right) MSNs in control and D2R-0E animals ( $500 \mathrm{~ms}$ current pulses from $-140 \mathrm{pA}$ to rheobase in $20 \mathrm{pA} \mathrm{steps).} \mathrm{Note} \mathrm{the} \mathrm{depolarized} \mathrm{resting} \mathrm{membrane} \mathrm{potential,} \mathrm{decreased} \mathrm{inward} \mathrm{rectification} \mathrm{and}$ decreased rheobase (striatopallidal: control, 140 pA;D2R-0E, $60 \mathrm{pA}$; striatonigral: control, 180 pA; D2R-0E, $100 \mathrm{pA}$ ) in the D2R-0E mice. Green traces show the action potential elicited at $200 \mathrm{pA}$. Note the respective increase in spike frequency for both MSN populations in the D2R-0E mice (striatopallidal: control, $19 \mathrm{~Hz}$; D2R-0E, 29 Hz; striatonigral: control, $21 \mathrm{~Hz}$; D2R-0E, $27 \mathrm{~Hz}$ ). c, $\boldsymbol{d}$, Current-voltage (c) and input- output ( $\boldsymbol{d}$ ) curves obtained for striatopallidal (left) and striatonigral (right) MSNs are significantly different between both genotypes (c, striatopallidal, $p<0.0001$; striatonigral, $p<0.0001$; $\boldsymbol{d}$, striatopallidal, $p<0.0001$; striatonigral, $p<0.0001)$.e, Box plots depicting the distribution of basic electrical properties of striatopallidal and striatonigral MSNs in control and D2R-0E mice (bars, min/max values; box, lower/upper quartile; line, median). ${ }^{*} p<0.05,{ }^{* *} p<0.01,{ }^{* * *} p<0.001,{ }^{* * * *} p<0.0001$. c e , striatopallidal: control, $n=27$ cells (11 mice); D2R-0E, $n=31$ (11); striatonigral: control, $n=$ 19(4); D2R-OE, $n=15$ (4). 


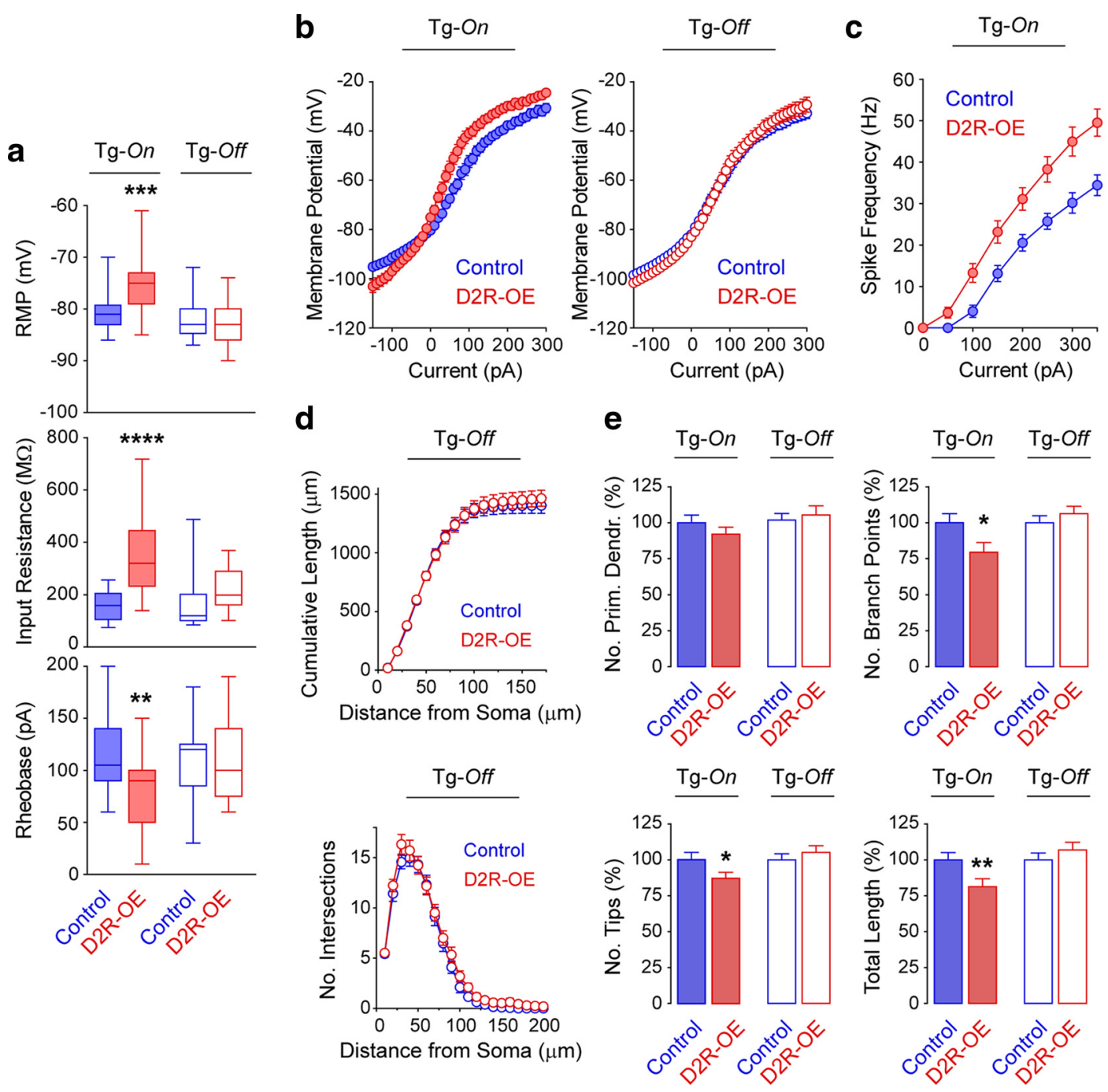

Figure 3. Restoring D2 receptor expression to normal levels in adult mice reverses the changes in excitability and dendritic morphology. $\boldsymbol{a}$, Box plots (bars, min/max values; box, lower/upper quartile; line, median) showing RMP, input resistance and rheobase of striatopallidal MSNs in 3-month-old control and D2R-OE mice in normal condition (Tg-On) or after treatment with doxycycline (Tg-Off). ${ }^{* *} p<0.01,{ }^{* * *} p<0.001,{ }^{* * * *} p<0.0001 . \boldsymbol{b}, \boldsymbol{c}$, Current-voltage $(\boldsymbol{b})$ and input- output (c) curves in 3-month-old D2R-0E mice are significantly different from controls $(\boldsymbol{b}, \boldsymbol{p}<0.0001$; $c, p<0.0001$ ) and are reversed when transgenic D2R overexpression is turned off. Tg-On: control, $n=21$ (4); D2R-OE, $n=19(4) ;$ Tg-Off: control, $n=21$ (7); D2R-0E, $n=24$ (5). $d$, The morphological atrophy observed in 3-month-old D2R-0E mice is reversed after 2 weeks of doxycycline treatment. Control, $n=21$ (6); D2R-0E, $n=21$ (5). $\boldsymbol{e}$, Total number of primary dendrites, branch points, branch tips and arbor length in control and D2R-OE mice treated (Tg-Off) or not (Tg-On) with doxycycline. Tg-On: control, $n=36$ (6); D2R-0E, $n=26(6) ; \mathrm{Tg}-0$ fff: control, $n=21$ (6); D2R-0E, $n=21(5) .{ }^{*} p<0.05,{ }^{* *} p<0.01$.

$\mathrm{mg} / \mathrm{kg}$ food) for 2 weeks, a protocol that we have shown is sufficient to normalize receptor levels in D2R-OE mice (Kellendonk et al., 2006). We found that restoring receptor levels to normal in the adult also reversed the changes in passive membrane properties and spiking frequency of striatopallidal MSNs (Fig. 3).

We then asked whether the changes in dendritic morphology are also reversible in the adult animal. To address this, 10-weekold D2R-OE and control mice were treated with doxycycline for 2 weeks and the morphology of dorsal striatum MSNs was analyzed using Golgi-Cox staining and 3-D Sholl analysis. Remarkably, the decreases in cumulative length, branch complexity, branch tips and total tree length previously observed in 3-monthold D2R-OE mice were absent when D2R-OE mice were treated for 2 weeks with doxycycline (Fig. 3d,e). These observations are consistent with a dynamic regulation of MSNs excitability and morphology by striatal D2Rs in the adult animal.

\section{Striatal D2R upregulation decreases expression of inward} rectifying potassium channels

The efflux of $\mathrm{K}^{+}$through so-called "inwardly rectifying" potassium channels regulates MSN excitability and is thought to maintain MSNs in a hyperpolarized "down state" in anesthetized animals in vivo (Nisenbaum and Wilson, 1995; Wilson and Kawaguchi, 1996; Mermelstein et al., 1998). The depolarized membrane potential and increased input resistance observed in the D2R-OE mice suggested to us that $I_{\text {Kir }}$ of MSNs may be altered in these animals. To measure $I_{\text {Kir }}$, we performed voltage-clamp recordings in striatopallidal and striatonigral MSNs. The membrane potential was first held at rest $(-80 \mathrm{mV})$, then stepped to a series of hyperpolarized test potentials. $I_{\mathrm{Kir}}$ was isolated by subtracting the current families recorded in the presence and the absence of cesium (Nisenbaum and Wilson, 1995; Mermelstein et al., 1998) (Fig. 4a). We measured a $40-50 \%$ reduction in the cesium-sensitive inward current in both striatopallidal and stria- 
a

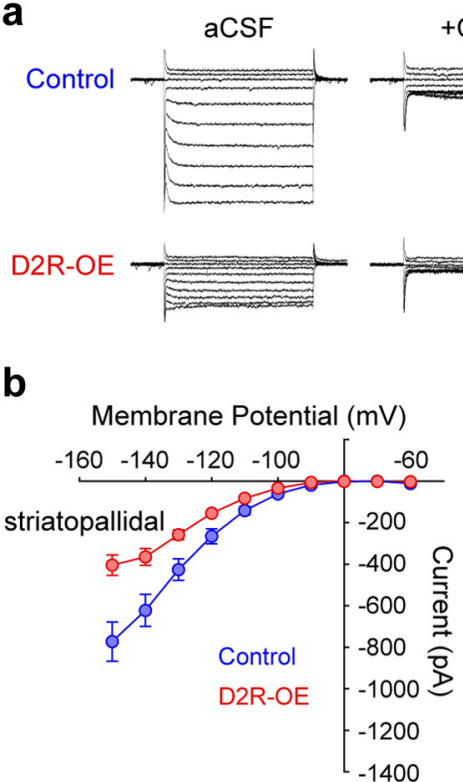

d
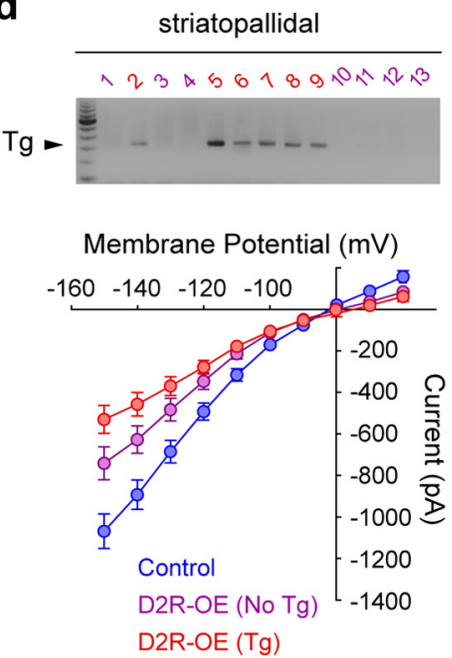

f

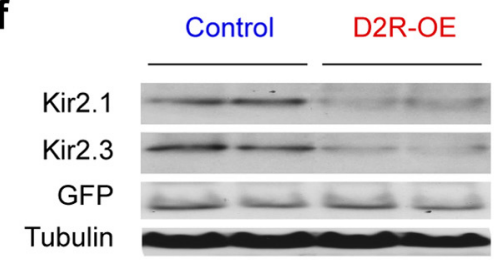

g

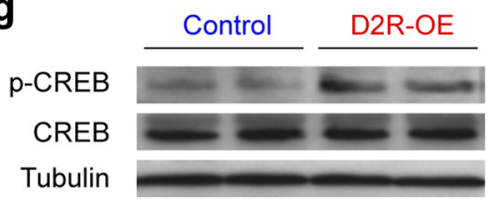

C

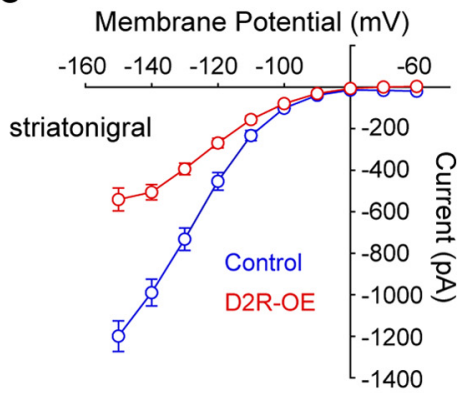

e
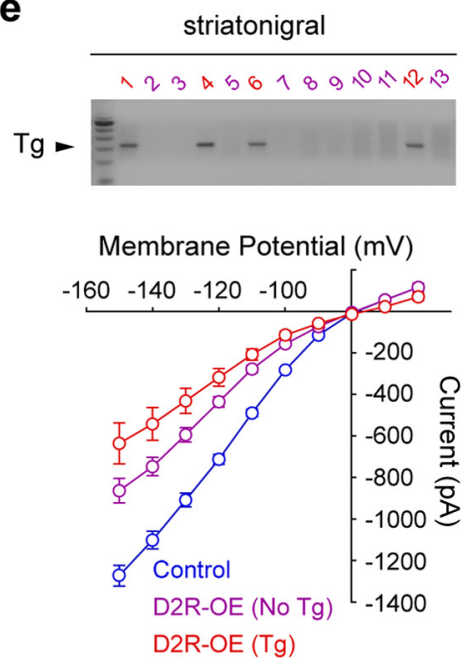

Control $\square$ D2R-OE
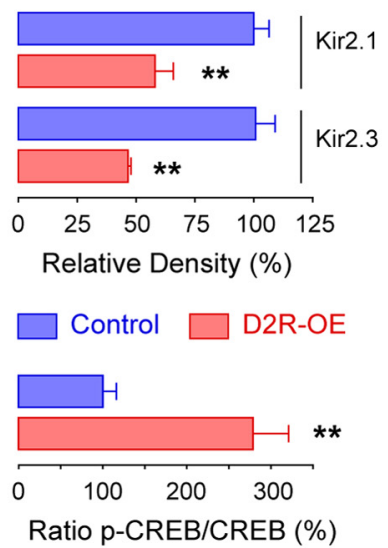

Figure 4. D2R overexpression decreases striatal inward rectifying currents through downregulation of Kir2 channel expression. $\boldsymbol{a}$, Representative inward rectifying currents obtained for negative membrane potentials ( -60 to $-150 \mathrm{mV}$ in $10 \mathrm{mV}$ steps) in control and D2R-0E mice. Kir channel currents ( $\left.I_{\text {Kir }}\right)$ are isolated by subtracting remaining currents in presence of Cesium ( $+\mathrm{Cs} C \mathrm{Cl}$ to total currents (aCSF). $\boldsymbol{b}, \boldsymbol{c}$, Current-voltage curves for K Kir $_{\text {in }}$ striatopallidal ( $\boldsymbol{b}$ ) and striatonigral (c) MSNs from control and D2R-OE mice calculated in $\boldsymbol{a}$. Striatopallidal: Control, $n=15$ (5); D2R-OE, $n=15$ (4). Striatonigral: Control, $n=15$ (4); D2R-0E, $n=15$ (4). $\boldsymbol{d}, \boldsymbol{e}$, Inward rectifying currents obtained for control or transgene-negative and transgene-positive striatopallidal $(\boldsymbol{d})$ and striatonigral (e) MSNs, as determined by single-cell RT-PCR. For better single-cell PCR quality, the cesium step has been omitted (see Materials and Methods). Currents are significantly altered (overall group effect: $\boldsymbol{d}, p<0.0001 ; \boldsymbol{e}, p<0.0001$ ). Individual

tonigral MSNs of D2R-OE mice compared with their control littermates (Fig. $4 b, c)$.

In the original description of $\mathrm{D} 2 \mathrm{R}-\mathrm{OE}$ mice we observed that the transgene is expressed only in $30 \%$ of MSNs in the dorsal striatum (Kellendonk et al., 2006; Drew et al., 2007). However, the changes in RMP, input resistance, rheobase and $I_{\mathrm{Kir}}$ are altered in all MSNs, suggesting a network effect that may act in addition to a cellautonomous effect. Therefore, the excitability of transgene-negative MSNs should also be enhanced in D2R-OE mice. To test this idea, we recorded from striatopallidal and striatonigral MSNs and determined the transgene expression postrecording via single-cell RT-PCR. Because single-cell RT-PCR is negatively affected by long recording durations, we focused on measuring inward rectifying currents that are central to the changes in MSN excitability observed here (Fig. $4 d, e)$. We found that $33 \%$ of MSNs, distributed in $40 \%$ (17/42) of striatopallidal and 26\% (9/34) of striatonigral MSNs, express the transgene. We further found that inward currents of D2R-OE mice are reduced by $30 \%$ in transgene-negative MSNs and by $50 \%$ in transgene-positive MSNs when compared with MSNs of control mice (Fig. 4d,e). This suggests that transgene-negative MSNs in D2R-OE mice are hyperexcitable due to a network effect elicited by the transgene-positive cells.

To determine whether the decrease in $I_{\text {Kir }}$ was associated with a decrease in Kir channel protein levels, we performed immunoblots using antibodies to Kir2.1 and Kir2.3, the two main Kir channels expressed in striatal MSNs (Karschin et al., 1996), in the striatum of control/Drd2-

\section{$\leftarrow$}

comparisons show significant differences between the three groups (control, Tg-negative D2R-OE and Tg-positive D2R-OE MSNs; $p<0.05$ ). Striatopallidal: control, $n=19$ (3); Tgnegative D2R-0E, $n=21$ (4); Tg-positive D2R-0E, $n=12$ (4). Striatonigral: control, $n=17$ (3); Tg-negative D2R-0E, $n=18$ (3); Tg-positive D2R-0E, $n=6$ (3). Single-cell RT-PCR revealed that $40 \%(17 / 42, n=4$ mice) of striatopallidal MSNs and $26 \%$ $(9 / 34, n=3$ mice) of striatonigral MSNs express the transgene. Representative gels from two mice are shown (magenta, transgene-negative; red, transgene-positive). $f$, Immunoblot analysis of striatal Kir2.1 and Kir2.3 protein expression in control and D2R-0E mice. Two examples of each genotype are shown. The densitometric quantification of Kir2. 1 and Kir2.3 is expressed as a percentage of control values after correction for GFP and tubulin. $n=3$ mice/group. ${ }^{* *} p<$ 0.01.g, Immunoblot analysis of CREB activity in the striatum of control and D2R-OE mice. The quantification is expressed as a ratio between $p($ Ser33)-CREB and total CREB proteins in percentage of control values. $n=4$ mice/group. ${ }^{* *} p<0.01$. 


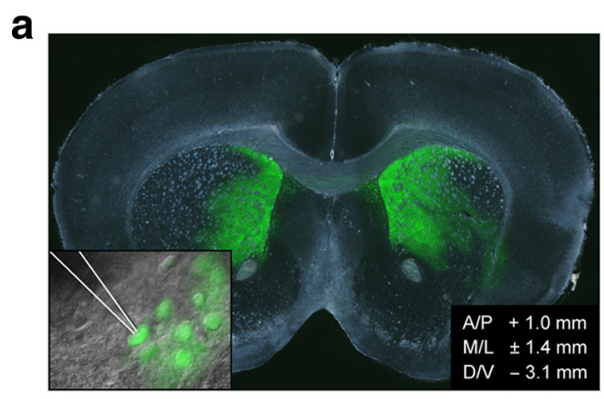

C
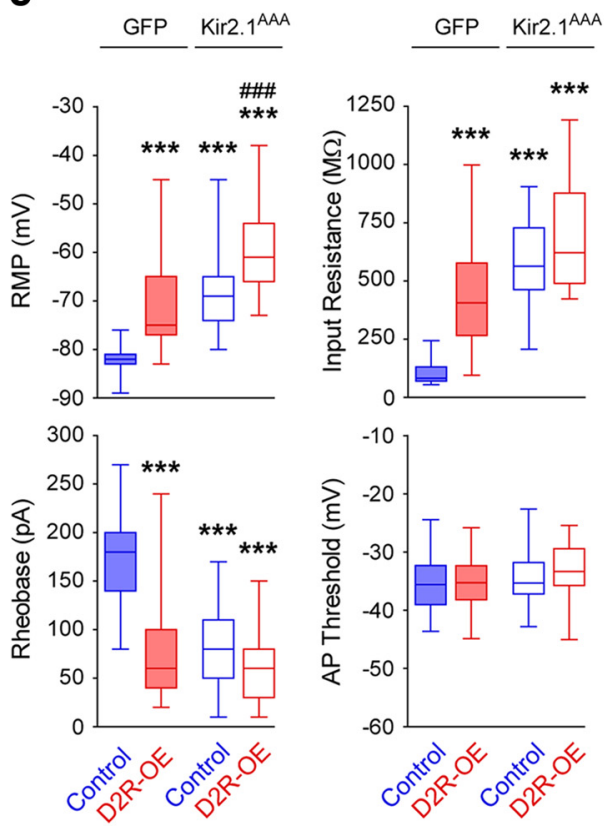

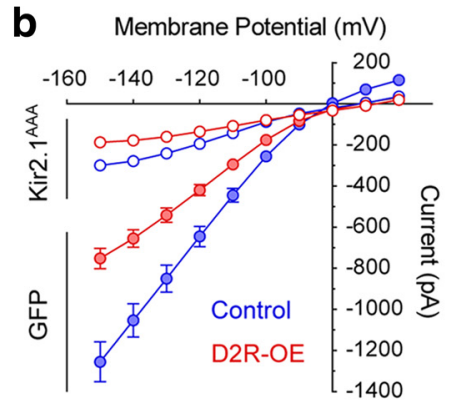

d

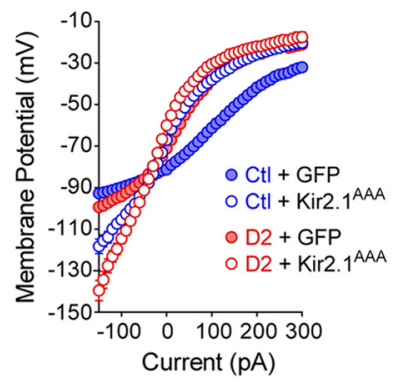

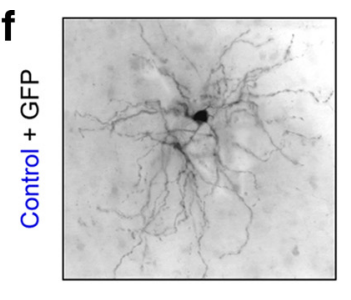
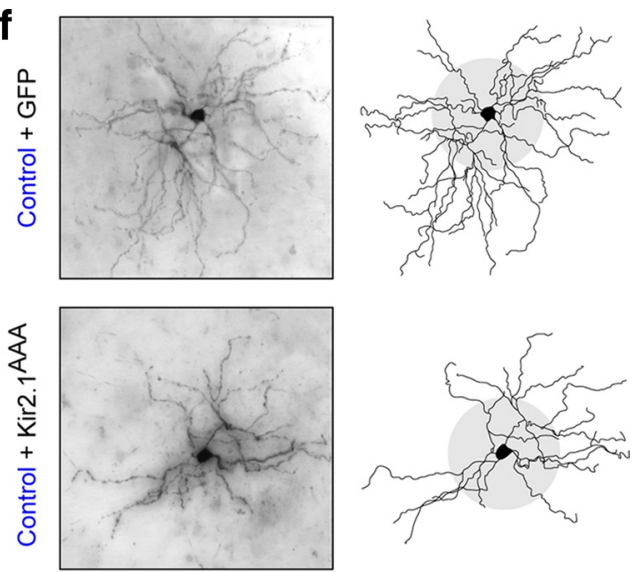

g

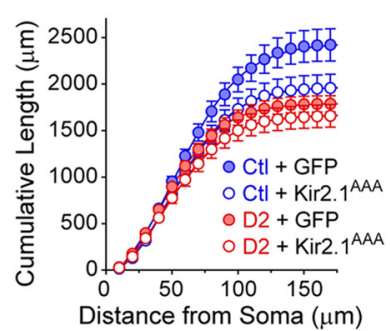

h

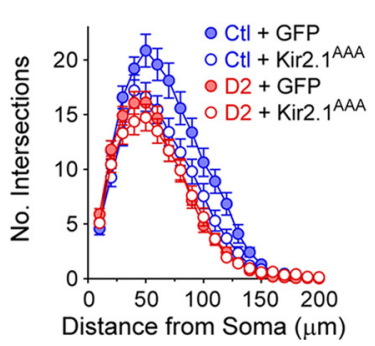

Figure 5. Striatal expression of the dominant-negative Kir2.1 ${ }^{\text {AAA }}$ channel is sufficient to induce MSN hyperexcitability and dendritic atrophy. $\boldsymbol{a}$, Representative coronal section showing GFP autofluorescence 1 month after viral injection in the dorsomedial striatum (2.5 $\times$ magnification). Insets show AAV2/1-GFP infected MSNs from a slice recording and coordinates of injections. $\boldsymbol{b}$, Inward currents at negative voltages obtained for GFP- and Kir2.1 $1^{\text {AAA }}$-infected control and D2R-0E MSNs. There is a significant effect of genotype $(p<0.0001)$ and of Kir $2.1^{\text {AAA }}$ expression $(p<0.0001)$. $c$, Distribution of basic electrical properties of GFP- and Kir2. $1^{\text {AAA }}$-expressing MSNs in control and D2R-0E mice (bars, min/max values; box, lower/upper quartile; line, median). ${ }^{* * *} p<0.001$, individual groups compared with control + GFP; ${ }^{\# \#} p<0.001, D 2 R-0 E+K i r 2.1^{\mathrm{AAA}}$ compared with D2R-0E + GFP.d, $\boldsymbol{e}$, Current-voltage (d) and input- output (e) curves are significantly altered (overall group effect: $\boldsymbol{d}, p<$ $0.0001 ; \boldsymbol{e}, p<0.0001$ ). Individual comparisons show significant changes in the three test groups (control + Kir2. ${ }^{\text {AAA }}, \mathrm{D} 2 \mathrm{R}-0 \mathrm{E}+\mathrm{GFP}, \mathrm{D} 2 \mathrm{R}-0 \mathrm{E}+\mathrm{Kir} 2.1^{\mathrm{AAA}}$ ), compared with the control + GFP group (all $p<$ 0.05). There was no significant difference between the test groups. Control $+\mathrm{GFP}, n=26$ cells ( 5 mice); D2R-OE + GFP, $n=36(5) ; \operatorname{control}+\mathrm{Kir} 2.1^{\mathrm{AAA}}, n=29(6) ; \mathrm{D} 2 \mathrm{R}-0 \mathrm{E}+\mathrm{Kir} 2.1^{\mathrm{AAA}}, n=30$ (6). $\boldsymbol{f}$ Representative biocytin-filled MSNs and corresponding Neurolucida reconstructions from control mice injected with either GFP or Kir2.1 ${ }^{\text {AAA }}$ virus (40X magnification). Gray circle radius, $50 \mu$ m. $\boldsymbol{g}, \boldsymbol{h}, 3-\mathrm{D}$ Sholl analysis demonstrates a change in cumulative length $(\boldsymbol{g})$ and complexity $(\boldsymbol{h})$ (overall group effect $\boldsymbol{g}, \boldsymbol{p}<0.005 ; \boldsymbol{h}, \boldsymbol{p}<0.0005$ ). Individual comparisons show significant decreases in the three test groups (control + Kir2.1 ${ }^{\text {AAA }}, \mathrm{D} 2 \mathrm{R}-0 \mathrm{E}+\mathrm{GFP}, \mathrm{D} 2 \mathrm{R}-0 \mathrm{E}+\mathrm{Kir} 2.1^{\mathrm{AAA}}$ ) compared with the control + GFP group (all $\left.p<0.05\right)$. There were no significant differences between the

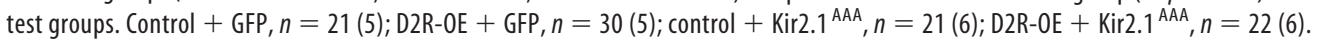

GFP and D2R-OE/Drd2-GFP mice. Both Kir2.1 and Kir2.3 protein levels were decreased by $\sim 50 \%$ in the striatum of D2R-OE mice compared with controls (Fig. 4f). Using gene chip analysis (Affymetrix Gene Chips 430A), we found that the mRNA for the Kir channel with the highest expression in the striatum, Kir2.3 (Kcnj4) (Karschin et al., 1996), was significantly downregulated in D2R-OE mice (control vs D2R-OE: $1239.7 \pm 35.3$ vs $1007.8 \pm$ $32.2 ; n=5$ mice/group, $p<0.001$ ). Expression of Kir2.3 mRNA returned to control levels after switching off the transgene for 2 weeks with doxycycline (control on doxycycline vs D2R-OE on doxycycline: $1012.4 \pm 149.5$ vs $1028.1 \pm 191.2 ; n=5$ mice/ group, $p=0.94$ ).

We next investigated a possible mechanism for the decrease in Kir2.3 mRNA expression. Virally mediated overexpression of the transcription factor CREB in its activated form has been shown to downregulate Kir2.3 mRNA in the NAc and to increase MSN excitability (Wallace et al., 2009). Moreover, acute and repeated treatment with the $\mathrm{D} 2 \mathrm{R}$ agonist quinpirole activated CREB in the striatum, as measured by an increase in the phosphorylation level of CREB at Serine 133 (p-CREB) (Yan et al., 1999; Culm et al., 2004). We therefore analyzed p-CREB levels in the striatum of D2R-OE and control mice (Fig. $4 g$ ). We found a threefold increase in p-CREB levels in D2R-OE mice, consistent with the idea that chronic D2R upregulation might control Kir channel expression by modulating CREB activity in the striatum.

\section{Kir downregulation is sufficient to induce changes in MSN excitability and morphology}

To determine the relationship between neuronal excitability and MSN morphology, we tested whether Kir downregulation, as observed in D2R-OE mice, is sufficient to increase excitability and decrease dendritic arborization. Using an adeno-associated virus (AAV2/1), we overexpressed a dominant-negative form of Kir2.1 (Kir2.1 ${ }^{\mathrm{AAA}}$ ) selectively in the striatum. In Kir2.1 ${ }^{\mathrm{AAA}}$ channels, 
the GYG motif of the pore region is replaced by three alanine residues (AAA), resulting in a dominant-negative channel that impairs endogenous Kir2.1 and Kir2.3 function (Preisig-Müller et al., 2002). The dorsomedial striatum of 2-month-old D2R-OE and control mice were injected with AAV2/1-Kir2.1 ${ }^{\mathrm{AAA}}$-IRESGFP or AAV2/1-GFP. MSN excitability and dendritic morphology were analyzed at 3 month of age (Fig. $5 a$ ). Because in D2R-OE mice excitability was upregulated in both Drd1 - and Drd2-MSNs (Fig. 1), we studied both populations at the same time. Mice were analyzed 4 weeks after viral injection to allow for the virus to be fully expressed and for sufficient time for potential morphological consequences to arise. Virus-infected MSNs were identified by GFP expression and slow depolarizing ramp potential. In addition, we verified their identity as medium spiny neurons by morphological examination after biocytin filling during the recordings.

We first verified that Kir2.1 ${ }^{\text {AAA }}$ expression has a dominantnegative effect in vivo. Using whole-cell current-clamp recordings, we measured an $80-90 \%$ reduction of inward currents at negative voltages in control and D2R-OE mice injected with Kir2.1 ${ }^{\text {AAA }}$ (Fig. 5b). Viral expression of Kir2.1 ${ }^{\text {AAA }}$ in control mice resulted in a depolarized $\mathrm{RMP}(-67.8 \pm 1.6 \mathrm{mV}, p<0.001)$, increased input resistance $(587 \pm 35 \mathrm{M} \Omega, p<0.001)$ and decreased rheobase $(83 \pm 8 \mathrm{pA}, p<0.001)$ compared with GFPinjected control mice. The changes in excitability induced by Kir2.1 ${ }^{\text {AAA }}$ (control/Kir2.1 ${ }^{\text {AAA }}$ mice) were similar to those induced by D2R overexpression (D2R-OE/GFP mice) (Fig. $5 c, d$ ). The viral expression of Kir2.1 ${ }^{\mathrm{AAA}}$ in D2R-OE mice did not elicit additional changes in passive membrane properties, with the exception of the RMP which became more depolarized $(-59.8 \pm$ $1.6 \mathrm{mV}, p<0.001$ ) compared with D2R-OE/GFP MSNs (Fig. 5c). Overall, the passive membrane properties and the current-voltage relationship of control/Kir2.1 ${ }^{\text {AAA }} \mathrm{MSNs}$ were remarkably similar to those of D2R-OE/GFP and D2R-OE/Kir2.1 ${ }^{\text {AAA }}$ MSNs (Fig. $5 c, d$ ). Likewise, the firing pattern of control/Kir2.1 ${ }^{\mathrm{AAA}}$, D2R-OE/GFP and D2R-OE/Kir2.1 ${ }^{\text {AAA }}$ MSNs were statistically indistinguishable, whereas all three groups differed from control/ GFP MSNs (Fig. 5e). Together, these observations demonstrate that Kir channel downregulation is sufficient to induce the changes in excitability observed in D2R-OE mice. Why a 50\% downregulation of inward rectifying currents in D2R-OE mice leads to comparable increases in excitability as an $80-90 \%$ downregulation in Kir2.1 ${ }^{\mathrm{AAA}}$-injected mice is unknown. One possibility is that the effects of Kir downregulation are reaching a physiological ceiling.

We then determined the consequences of increased excitability on dendritic morphology by filling virus-infected MSNs with biocytin during the recording procedure (Fig. $5 f$ ) and performing subsequent three-dimensional neuron reconstructions. This revealed that dendritic length and complexity of control/ Kir2.1 ${ }^{\text {AAA }}$, D2R-OE/GFP and D2R-OE/Kir2.1 ${ }^{\text {AAA }}$-MSNs were significantly decreased compared with control/GFP MSNs, but did not significantly differ from each other (Fig. $5 g, h$ ). This was also reflected in a reduction of total tree length, number of branch nodes and tips (data not shown). These results suggest that Kir downregulation alone is sufficient to recapitulate fully the changes in excitability and morphology that we observed in D2R-OE mice.

Striatal atrophy is partially reversed after restoring normal D2R levels in adult D2R-OE mice

Could the decrease in dendritic morphology be responsible for the decrease in striatal volume observed in D2R-OE mice? To
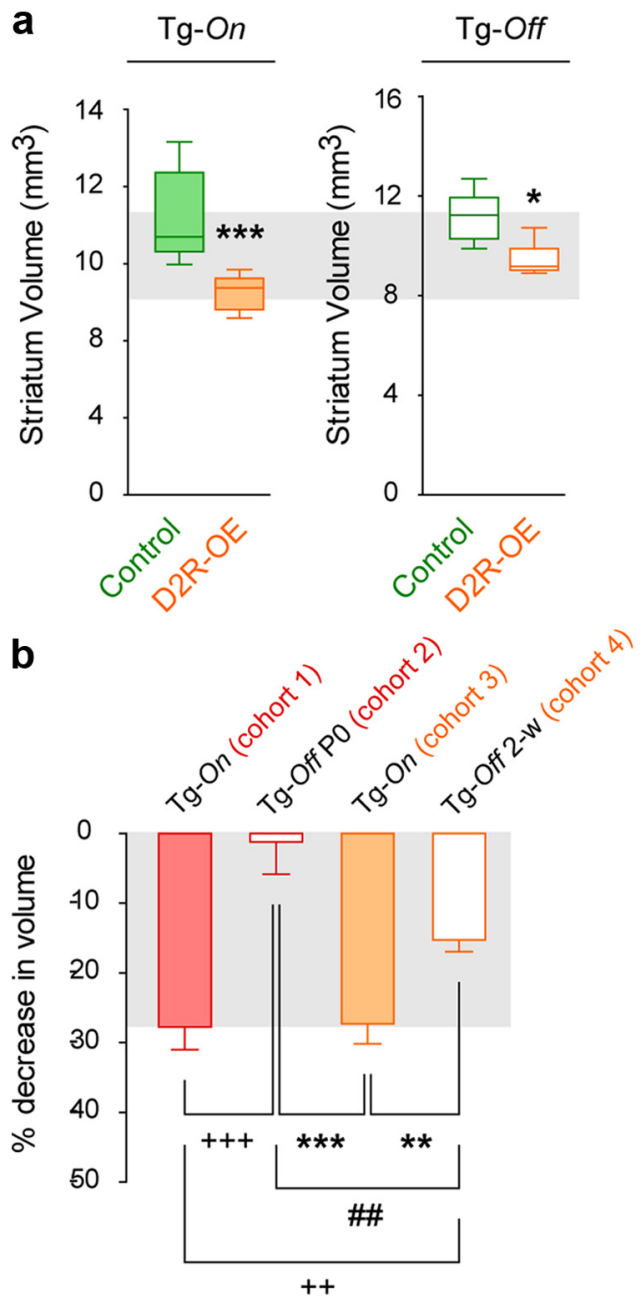

Figure 6. Decreased striatal volume is reversible in adult D2R-OE mice. $\boldsymbol{a}$, Striatal volumetric analysis of 3- to 4-month-old control and D2R-OE mice fed with regular laboratory chow (Tg-On) or doxycycline-supplemented chow for 2 weeks (Tg-Off). ${ }^{*} p<0.05$, ${ }^{* * *} p<0.001$. Tg-On, $n=5$ mice/group; Tg-Off, $n=10$ mice/group. $\boldsymbol{b}$, One-way ANOVA and post hoc analyzes of the relative decrease in striatal volume showed significant differences between the cohorts expressing the transgene (Tg-On, cohorts 1 and 3) and cohorts that were fed with doxycycline (since birth: $\mathrm{Tg}-\mathrm{Off} \mathrm{PO}$, cohort 2; for only 2 weeks: Tg-Off2-w, cohort 4). Cohort 1 vs cohorts 2 and $4,{ }^{2+} p<0.01,{ }^{++}{ }^{+} p<$ 0.001; Cohort 3 vs cohorts 2 and $4,{ }^{* *} p<0.01,{ }^{* * *} p<0.001$. A significant difference was also observed between the 2 cohorts on doxycycline. Cohort 2 vs $4,{ }^{\#} p<0.01$.

address this question, we treated adult D2R-OE mice and their control littermates (3-4 months of age) with doxycycline for 2 weeks and estimated the striatal volume of both groups. We found that the volumetric decrease is partially (50\%) reversed after 2 weeks of doxycycline treatment in adult animals (Fig. 6). This suggests that at least a part of the volumetric decrease may be due to the changes in dendritic morphology which themselves are fully reversed after the same treatment period (Fig. $3 d$ ).

\section{Discussion}

Using transgenic mice that selectively overexpress D2Rs in the MSNs of the striatum we demonstrate that D2Rs dynamically regulate excitability and dendritic arborization in the adult animal. Overexpression of D2Rs increases the excitability of MSNs while decreasing the complexity of their dendritic arborization. These changes are associated with a downregulation of inward rectifying potassium channels and can be reversed in the adult animal after restoring D2 receptors to normal levels. We further identify Kir2 channel downregulation as the critical mediator for 
the changes in excitability and dendritic morphology because in vivo downregulation of Kir2 function on its own is sufficient to generate the changes in excitability and dendritic arborization observed in D2R transgenic mice.

In anesthetized animals, the in vivo membrane potential of striatal MSNs fluctuates between two stable states, the "up state," characterized by a depolarized RMP $(-55 \mathrm{mV})$, which facilitates action potential firing, and the down state, denoted by its relatively hyperpolarized RMP $(-80 \mathrm{mV})$ (Wilson and Kawaguchi, 1996). Between these two states, the membrane potential of MSNs is less stable, with the membrane resistance increasing sharply above $-75 \mathrm{mV}$. This enables strong synchronized inputs from the cortex, hippocampus and thalamus to efficiently drive MSNs from the down state to the up state, where they will discharge. The efflux of $\mathrm{K}^{+}$through Kir channels is responsible for maintaining MSNs in the hyperpolarized down state, by damping the response of MSNs in response to small perturbations of membrane potential around RMP. In this way, Kir channels not only set the level of RMP but also allow the striatum to filter out irrelevant incoming inputs (Nisenbaum and Wilson, 1995; Wilson and Kawaguchi, 1996; Mermelstein et al., 1998).

The acute activation of D2Rs has been shown to inhibit the excitability of dopaminergic midbrain neurons via G-proteincoupled inward rectifying $\mathrm{K}^{+}$channels (Innis and Aghajanian, 1987; Lacey et al., 1987). In contrast, the effects of acute D2R activation on MSNs excitability are ambiguous and examples of D2 receptor activation decreasing and increasing excitability have been reported (Surmeier and Kitai, 1993; Greif et al., 1995; Hernandez-Lopez et al., 2000; Cepeda et al., 2001; Hopf et al., 2003; Perez et al., 2006). In the NAc, D2R-mediated inhibition of the cAMP/PKA pathway increases voltage-dependent slowinactivating A-type $\mathrm{K}^{+}$currents $\left(I_{\mathrm{AS}}\right)$, which leads to a decrease in MSN excitability and delayed action potential firing (Perez et al., 2006). In contrast, D2R-mediated activation of the PLC pathway reduces $I_{\text {Kir }}$, which increases membrane resistance and therefore enhances NAc MSN excitability (Perez et al., 2006). Because these $\mathrm{K}^{+}$channels are active over different ranges of membrane potentials, the acute activation of D2Rs can exert opposite effects on excitability depending on the state of the cell.

In contrast, little is currently known of the consequences of chronic activation of D2Rs on MSN excitability. Here, we show that chronic upregulation of D2 receptors increases the excitability of both striatopallidal and striatonigral MSN via downregulation of Kir channel expression. The effect of chronic D2R upregulation is therefore distinct from what was previously observed with acute Kir channel modulation, since it is mediated by altered levels of channel expression, rather than by posttranslational regulation.

To determine whether downregulation of Kir channels is sufficient to explain the effects of D2R upregulation on intrinsic excitability, we overexpressed a dominant-negative mutant Kir2.1 channel in the striatum in vivo. Inward currents and inward rectification were strongly decreased in D2R-OE and control mice that were infected with AAV2/1-Kir2.1 AAA-IRES-GFP. In consequence, Kir2.1 ${ }^{\mathrm{AAA}}$-expressing MSNs showed depolarized RMP, decreased rheobase and increased input resistance, all indicative of increased excitability. Surprisingly, we found that the expression of Kir2.1 ${ }^{\mathrm{AAA}}$ in wild-type mice also affected the current-voltage relationship over a range of voltages where $I_{\text {Kir }}$ is usually inactivated $(>-60 \mathrm{mV})$, and in which the currentvoltage relationship is primarily influenced by voltage-gated calcium and A-type or M-type potassium channels rather than Kir channels. These results suggest that in striatal MSNs Kir chan- nel expression levels may indirectly affect the function of other voltage-gated channels. We also observed that the passive membrane properties of D2R-OE mice injected with the control virus were surprisingly similar to those of control mice injected with the Kir2.1 ${ }^{\mathrm{AAA}}$ virus. This observation suggests that downregulation of $I_{\text {Kir }}$ may be the predominant mechanism by which D2R upregulation affects MSN excitability.

In addition to increased excitability in MSNs, we also observed a progressive atrophy of their dendritic arbors in D2R-OE mice. Increased excitability of MSNs has been discussed as an important factor in Parkinson's disease, and the dendritic atrophy and spine loss observed in patients or animal models of Parkinson's disease have been associated with increased membrane excitability (McNeill et al., 1988; Tseng et al., 2001; ZajaMilatovic et al., 2005; Day et al., 2006). The mechanism for the hyperexcitability in these animal models is unknown but the downregulation of potassium channels (A-type and Kir) has been proposed, although in this context, as a consequence of decreased D2R activation in either MSNs or cholinergic interneurons (Shen et al., 2007; Azdad et al., 2009). While it has been postulated that hyperexcitability is responsible for the dendritic atrophy and spine loss (Day et al., 2006), no direct link between increased MSN excitability and changes in dendritic morphology has been established. Our data provide such a connection for the first time by showing that downregulation of Kir channels is sufficient to induce dendritic atrophy in MSNs.

Why a model of dopamine loss leads to a similar phenotype as a model of D2R upregulation is unclear. This could be due to different experimental conditions between D2R-OE mice and the described Parkinson's models. In fact, in D2R-OE mice the receptors are chronically upregulated specifically in MSNs of the striatum starting from early development. In the Parkinson's animal models, dopamine loss is induced during adolescence either by targeting subchronically one hemisphere or by targeting acutely all dopaminergic projections in the brain, thereby affecting many cell types. Since a network effect plays an important role in our observations these models may not be comparable.

In the $\mathrm{D} 2 \mathrm{R}-\mathrm{OE}$ mice, transgene expression is restricted to $\sim 30 \%$ of MSNs in the dorsal striatum (Kellendonk et al., 2006; Drew et al., 2007). Nevertheless, inward rectifying currents are reduced in all MSNs of D2R-OE mice, with transgene-expressing and non-expressing MSNs displaying a 50\% and 30\% reduction in inward currents, respectively. This suggests a cell-autonomous effect in the transgene-expressing MSNs as well as a network effect affecting the non-expressing cells. This network effect could be mediated by intrastriatal MSN-MSN interactions or via MSN-interneuron-MSN interactions. Alternatively, it could be mediated via long-range connections. In line with this interpretation, we have found that the medial prefrontal cortex is altered in D2R-OE mice in a reversible manner (Li et al., 2011). It is therefore conceivable that selective upregulation of D2Rs in the striatum may affect MSN excitability indirectly via its secondary impact on the prefrontal cortex.

Historically, MSNs are thought to be separated into two populations, the D1R-positive (striatonigral) and the D2R-positive (striatopallidal) MSNs. The degree of overlap has been a long debate and varies depending on the technique used to detect receptor expression (Bertran-Gonzalez et al., 2010). Using singlecell PCR Surmeier et al. found that $\sim 20 \%$ of Drd1a/Substance P mRNA-positive MSNs coexpress D2Rs mRNA (Surmeier et al., 1996). Here, using single-cell PCR we found that $26 \%$ of striatonigral MSNs coexpress transgenic D2R mRNA. This should lead to an increase in the amount of MSNs coexpressing both 
receptors. Whether this increase in the percentage of D1R and D2R coexpressing is necessary or sufficient for the changes observed in excitability and morphology in all MSNs is currently unknown.

An elevation in D2 receptor density and occupancy is observed in the striatum of drug-free and drug-naive patients with schizophrenia (Simpson et al., 2010). A core component of the so-called negative symptoms of schizophrenia is a deficit in motivation, and this is a better predictor of the long-term prognosis for individual patients than are the positive (psychotic) symptoms (Buckley and Stahl, 2007; Gard et al., 2009). We recently reported that selective overexpression of D2R in the striatum of the mouse impairs incentive motivation, a deficit that was reversed after switching off excess D2R expression (Drew et al., 2007; Simpson et al., 2011). In the present study, we show that D2R overexpression is associated with reversible changes in MSN excitability and morphology, in both the dorsal and ventral striatum. Striatal MSNs are thought to be important for motivation because they integrate coordinated neuronal inputs from the prefrontal cortex and the amygdala that process motivational information. We hypothesize that a decrease in $I_{\text {Kir }}$ may facilitate a shift from the silent down state to the activated up state, and in combination with a decrease in dendritic surface, this augmented excitability in MSNs may impair the filtering of incoming neuronal information at the level of the striatum. We hypothesize that the changes in MSN excitability and morphology may also be present in patients with schizophrenia and could contribute to the motivational deficits of patients. Future studies measuring postmortem Kir channel protein levels could address this hypothesis.

A reduction in caudate volume has long been described in drug-naive schizophrenic patients, whereas in contrast, chronic treatment with D2R antagonists has been shown to increase caudate volume (Simpson et al., 2010). Here, we show that chronic $\mathrm{D} 2 \mathrm{R}$ upregulation leads to a decrease in the volume of the striatum in mice, which at least in part is mediated by the observed decrease in MSN dendritic arborization. The dendritic atrophy is reversed when the level of $\mathrm{D} 2$ receptors is restored to normal levels, demonstrating a surprisingly high degree of plasticity in the adult animal. We propose that the volumetric changes observed in patients could also partly be a consequence of D2Rregulated dendritic plasticity.

\section{References}

Azdad K, Chàvez M, Don Bischop P, Wetzelaer P, Marescau B, De Deyn PP, Gall D, Schiffmann SN (2009) Homeostatic plasticity of striatal neurons intrinsic excitability following dopamine depletion. PLoS One 4:e6908.

Bach ME, Simpson EH, Kahn L, Marshall JJ, Kandel ER, Kellendonk C (2008) Transient and selective overexpression of D2 receptors in the striatum causes persistent deficits in conditional associative learning. Proc Natl Acad Sci U S A 105:16027-16032.

Bertran-Gonzalez J, Herve D, Girault JA, Valjent E (2010) What is the degree of segregation between striatonigral and striatopallidal projections? Front Neuroanat 4:136.

Buckley PF, Stahl SM (2007) Pharmacological treatment of negative symptoms of schizophrenia: therapeutic opportunity or cul-de-sac? Acta Psychiatr Scand 115:93-100.

Cazorla M, Jouvenceau A, Rose C, Guilloux JP, Pilon C, Dranovsky A, Prémont J (2010) Cyclotraxin-B, the first highly potent and selective TrkB inhibitor, has anxiolytic properties in mice. PLoS One 5:e9777.

Cepeda C, Hurst RS, Altemus KL, Flores-Hernández J, Calvert CR, Jokel ES, Grandy DK, Low MJ, Rubinstein M, Ariano MA, Levine MS (2001) Facilitated glutamatergic transmission in the striatum of D2 dopamine receptor-deficient mice. J Neurophysiol 85:659-670.

Cepeda C, André VM, Yamazaki I, Wu N, Kleiman-Weiner M, Levine MS (2008) Differential electrophysiological properties of dopamine D1 and
D2 receptor-containing striatal medium-sized spiny neurons. Eur J Neurosci 27:671-682.

Chakos MH, Lieberman JA, Bilder RM, Borenstein M, Lerner G, Bogerts B, Wu H, Kinon B, Ashtari M (1994) Increase in caudate nuclei volumes of first-episode schizophrenic patients taking antipsychotic drugs. Am J Psychiatry 151:1430-1436.

Culm KE, Lugo-Escobar N, Hope BT, Hammer RP Jr (2004) Repeated quinpirole treatment increases cAMP-dependent protein kinase activity and CREB phosphorylation in nucleus accumbens and reverses quinpirole-induced sensorimotor gating deficits in rats. Neuropsychopharmacology 29:1823-1830.

Day M, Wang Z, Ding J, An X, Ingham CA, Shering AF, Wokosin D, Ilijic E, Sun Z, Sampson AR, Mugnaini E, Deutch AY, Sesack SR, Arbuthnott GW, Surmeier DJ (2006) Selective elimination of glutamatergic synapses on striatopallidal neurons in Parkinson disease models. Nat Neurosci 9:251-259.

Drew MR, Simpson EH, Kellendonk C, Herzberg WG, Lipatova O, Fairhurst S, Kandel ER, Malapani C, Balsam PD (2007) Transient overexpression of striatal D2 receptors impairs operant motivation and interval timing. J Neurosci 27:7731-7739.

Franklin BJK, Paxinos G (2008) The mouse brain in stereotaxic coordinates, Ed 3. San Diego: Academic.

Ebdrup BH, Glenthøj B, Rasmussen H, Aggernaes B, Langkilde AR, Paulson OB, Lublin H, Skimminge A, Baaré W (2010) Hippocampal and caudate volume reductions in antipsychotic-naive first-episode schizophrenia. J Psychiatry Neurosci 35:95-104.

Gard DE, Fisher M, Garrett C, Genevsky A, Vinogradov S (2009) Motivation and its relationship to neurocognition, social cognition, and functional outcome in schizophrenia. Schizophr Res 115:74-81.

Gertler TS, Chan CS, Surmeier DJ (2008) Dichotomous anatomical properties of adult striatal medium spiny neurons. J Neurosci 28:10814-10824.

Gong S, Zheng C, Doughty ML, Losos K, Didkovsky N, Schambra UB, Nowak NJ, Joyner A, Leblanc G, Hatten ME, Heintz N (2003) A gene expression atlas of the central nervous system based on bacterial artificial chromosomes. Nature 425:917-925.

Greif GJ, Lin YJ, Liu JC, Freedman JE (1995) Dopamine-modulated potassium channels on rat striatal neurons: specific activation and cellular expression. J Neurosci 15:4533-4544.

Hernandez-Lopez S, Tkatch T, Perez-Garci E, Galarraga E, Bargas J, Hamm $\mathrm{H}$, Surmeier DJ (2000) D2 dopamine receptors in striatal medium spiny neurons reduce L-type $\mathrm{Ca}^{2+}$ currents and excitability via a novel PLC[beta] 1-IP3-calcineurin-signaling cascade. J Neurosci 20:8987-8995.

Hopf FW, Cascini MG, Gordon AS, Diamond I, Bonci A (2003) Cooperative activation of dopamine D1 and D2 receptors increases spike firing of nucleus accumbens neurons via G-protein betagamma subunits. J Neurosci 23:5079-5087.

Innis RB, Aghajanian GK (1987) Pertussis toxin blocks autoreceptormediated inhibition of dopaminergic neurons in rat substantia nigra. Brain Res 411:139-143.

Jia F, Yue M, Chandra D, Keramidas A, Goldstein PA, Homanics GE, Harrison NL (2008) Taurine is a potent activator of extrasynaptic GABA(A) receptors in the thalamus. J Neurosci 28:106-115.

Karschin C, Dissmann E, Stühmer W, Karschin A (1996) IRK(1-3) and GIRK(1-4) inwardly rectifying K + channel mRNAs are differentially expressed in the adult rat brain. J Neurosci 16:3559-3570.

Kellendonk C, Simpson EH, Polan HJ, Malleret G, Vronskaya S, Winiger V, Moore H, Kandel ER (2006) Transient and selective overexpression of dopamine $\mathrm{D} 2$ receptors in the striatum causes persistent abnormalities in prefrontal cortex functioning. Neuron 49:603-615.

Keshavan MS, Bagwell WW, Haas GL, Sweeney JA, Schooler NR, Pettegrew JW (1994) Changes in caudate volume with neuroleptic treatment. Lancet 344:1434

Keshavan MS, Rosenberg D, Sweeney JA, Pettegrew JW (1998) Decreased caudate volume in neuroleptic-naive psychotic patients. Am J Psychiatry 155:774-778.

Kreitzer AC, Malenka RC (2007) Endocannabinoid-mediated rescue of striatal LTD and motor deficits in Parkinson's disease models. Nature 445:643-647.

Lacey MG, Mercuri NB, North RA (1987) Dopamine acts on D2 receptors to increase potassium conductance in neurones of the rat substantia nigra zona compacta. J Physiol 392:397-416. 
Laruelle M (1998) Imaging dopamine transmission in schizophrenia. A review and meta-analysis. Q J Nuclear Med 42:211-221.

Li YC, Kellendonk C, Simpson EH, Kandel ER, Gao WJ (2011) D2 receptor overexpression in the striatum leads to a deficit in inhibitory transmission and dopamine sensitivity in mouse prefrontal cortex. Proc Natl Acad Sci U S A 108:12107-12112.

Matamales M, Bertran-Gonzalez J, Salomon L, Degos B, Deniau JM, Valjent E, Hervé D, Girault JA (2009) Striatal medium-sized spiny neurons: identification by nuclear staining and study of neuronal subpopulations in BAC transgenic mice. PLoS One 4:e4770.

McNeill TH, Brown SA, Rafols JA, Shoulson I (1988) Atrophy of medium spiny I striatal dendrites in advanced Parkinson's disease. Brain Res 455:148-152.

Mermelstein PG, Song WJ, Tkatch T, Yan Z, Surmeier DJ (1998) Inwardly rectifying potassium (IRK) currents are correlated with IRK subunit expression in rat nucleus accumbens medium spiny neurons. J Neurosci 18:6650-6661.

Navari S, Dazzan P (2009) Do antipsychotic drugs affect brain structure? A systematic and critical review of MRI findings. Psychol Med 39:1763-1777.

Nisenbaum ES, Wilson CJ (1995) Potassium currents responsible for inward and outward rectification in rat neostriatal spiny projection neurons. J Neurosci 15:4449-4463.

Nisenbaum ES, Xu ZC, Wilson CJ (1994) Contribution of a slowly inactivating potassium current to the transition to firing of neostriatal spiny projection neurons. J Neurophysiol 71:1174-1189.

Perez MF, White FJ, Hu XT (2006) Dopamine D(2) receptor modulation of $\mathrm{K}(+)$ channel activity regulates excitability of nucleus accumbens neurons at different membrane potentials. J Neurophysiol 96:2217-2228.

Preisig-Müller R, Schlichthörl G, Goerge T, Heinen S, Brüggemann A, Rajan S, Derst C, Veh RW, Daut J (2002) Heteromerization of Kir2.x potassium channels contributes to the phenotype of Andersen's syndrome. Proc Natl Acad Sci U S A 99:7774-7779.

Robinson TE, Kolb B (2004) Structural plasticity associated with exposure to drugs of abuse. Neuropharmacology 47 [Suppl 1]:33-46.

Shen W, Tian X, Day M, Ulrich S, Tkatch T, Nathanson NM, Surmeier DJ
(2007) Cholinergic modulation of Kir2 channels selectively elevates dendritic excitability in striatopallidal neurons. Nat Neurosci 10:1458-1466.

Simpson EH, Kellendonk C, Kandel E (2010) A possible role for the striatum in the pathogenesis of the cognitive symptoms of schizophrenia. Neuron 65:585-596.

Simpson EH, Kellendonk C, Ward RD, Richards V, Lipatova O, Fairhurst S, Kandel ER, Balsam PD (2011) Pharmacologic rescue of motivational deficit in an animal model of the negative symptoms of schizophrenia. Biol Psychiatry 69:928-935.

Surmeier DJ, Kitai ST (1993) D1 and D2 dopamine receptor modulation of sodium and potassium currents in rat neostriatal neurons. Progress in brain research 99:309-324.

Surmeier DJ, Song WJ, Yan Z (1996) Coordinated expression of dopamine receptors in neostriatal medium spiny neurons. J Neurosci 16:6579-6591.

Tseng KY, Kasanetz F, Kargieman L, Riquelme LA, Murer MG (2001) Cortical slow oscillatory activity is reflected in the membrane potential and spike trains of striatal neurons in rats with chronic nigrostriatal lesions. J Neurosci 21:6430-6439.

Wallace DL, Han MH, Graham DL, Green TA, Vialou V, Iñiguez SD, Cao JL, Kirk A, Chakravarty S, Kumar A, Krishnan V, Neve RL, Cooper DC, Bolaños CA, Barrot M, McClung CA, Nestler EJ (2009) CREB regulation of nucleus accumbens excitability mediates social isolation-induced behavioral deficits. Nat Neurosci 12:200-209.

Ward RD, Kellendonk C, Simpson EH, Lipatova O, Drew MR, Fairhurst S, Kandel ER, Balsam PD (2009) Impaired timing precision produced by striatal D2 receptor overexpression is mediated by cognitive and motivational deficits. Behav Neurosci 123:720-730.

Wilson CJ, Kawaguchi Y (1996) The origins of two-state spontaneous membrane potential fluctuations of neostriatal spiny neurons. J Neurosci 16:2397-2410.

Yan Z, Feng J, Fienberg AA, Greengard P (1999) D(2) dopamine receptors induce mitogen-activated protein kinase and cAMP response elementbinding protein phosphorylation in neurons. Proc Natl Acad Sci U S A 96:11607-11612.

Zaja-Milatovic S, Milatovic D, Schantz AM, Zhang J, Montine KS, Samii A, Deutch AY, Montine TJ (2005) Dendritic degeneration in neostriatal medium spiny neurons in Parkinson disease. Neurology 64:545-547. 